\title{
Transnational Migration Aspirations, Educational Capabilities, Marriage Preferences, and Health Outcomes: A Mixed-Methods Study Among Pakistani youth
}

\author{
Aisha Jalil \\ University of Lahore \\ Florian Fischer ( $\nabla$ florian.fischer@rwu.de ) \\ Bielefeld University, School of Public Health https://orcid.org/0000-0002-4388-1245
}

Research article

Keywords: aspiration, mental health, skilled youth, transnational migration, Pakistan

Posted Date: June 22nd, 2020

DOI: https://doi.org/10.21203/rs.3.rs-34844/v1

License: (a) (1) This work is licensed under a Creative Commons Attribution 4.0 International License.

Read Full License 


\section{Abstract}

Background: Pakistani youths desire for international migration due to the more favourable socioeconomic circumstances in the country of destination. This may lead to migration marriages among partners of mismatching socio-economic statuses. This study aims to analyse the migration aspirations in relation with educational capabilities, marriage preferences, and health outcomes in the context of an anticipated transnational migration.

Methods: A sequential mixed-methods study has been conducted. Nine case studies and a selfadministered questionnaire survey among 496 students enrolled at University of Lahore, Pakistan, have been conducted. Qualitative data was analysed through thematic content analysis. Descriptive, bivariate, and multivariate analyses were performed for the quantitative data. The inductive themes in qualitative analysis, in addition to a literature review, were used to develop the structured questionnaire for the quantitative survey.

Results: Significant associations of socio-demographic characteristics (gender, age, and education), migration aspirations, educational capabilities, marriage preferences, and health outcomes with the anticipated immigration status were observed. The potential migrants acquire skills and education that may support their migration plans.

Conclusion: This study shows high intentions for transnational migration. Cautious policies need to be implemented for avoiding a brain drain, but also for allowing a high level of education and freedom to migrate.

\section{Background}

A great segment of skilled youth desires for attaining immigration status in wealthier countries because of the worse socio-economic circumstances in their country of origin. This migration can either be a permanent or a semi-permanent change of residence [1]. Population movements are a fundamental human endeavour that has been happening since the beginning of mankind. However, this far off displacement had been difficult in each historical era. In pre-industrial times, particularly the voyage itself was difficult, whereas in today's society, documentation and border crossing permissions are challenging. Furthermore, the process of transnational migration involves problems of cultural integration, language barriers, and financial and physical adjustment [2].

The International Organization of Migration defines a migrant as a person who has moved across the international borders away from his country of birth with the intent of settlement [3]. Migration marriage has been the dominant form of migration from Pakistan to European countries [4]. Several studies have demonstrated a continuous growth in migration marriages of south-Asian women in western countries [5]. In South Asia, marriages with immigrants have been sparked by cultural pressures and a wish for better life opportunities [1]. Frequently, young women from developing countries marry older men to offer beauty, youth and domesticity with traditional gender roles and companionship [6]. For example, the rural 
communities in Vietnam raise and send their women as brides to wealthier East Asian countries [7]. In Pakistan, parents are willing to give their daughters to man in any profession possessing permanent residence of wealthier countries, even aged or health-deprived ones. These marriages are arranged and do not involve consent of bride and groom in the majority of cases. The people of South Asian region dream for the life in developed countries, mostly in terms of financial prosperity. They uphold and love imitations of prosperous countries, however, have dual standards of judgements based on which they like some aspects and disapprove the others. There is gross approval of western personality grooming and English language, particularly in Pakistan. However, women's choice of dressing and appearing modern is disapproved. This is also a reason for perceived marginalisation among south Asians [8].

Sexual abstinence and virginity of girls are the cultural ideal tied to family respect in eastern cultures. Women in South Asian territory marry back in their home country primarily because of the family involvement and concern for ethnic prestige [9]. Such practices have complex contextual roots in cultural traditions of immigrant's identity, perceived cultural deviance, and quality of integration in country of settlement. Despite these cultural factors, the socio-economic conditions in Pakistan's society are pushing youth to seek immigration. Previously, the migration of Pakistani's to United Kingdom (UK) was characterised as for the family reunion [10]. However, in the last two decades, the social circumstances have changed largely.

The increased level of contact among nationals and non-nationals, internationalisation in education and employment, and the use of information technology and social media have contributed to migration marriages between South Asian possessing UK citizenship and immigrants from Pakistan. Empirical studies demonstrated that the Indian youth are more likely to adopt integration strategies as opposed to Pakistani Muslims who adopt a separation strategy while interacting with their host culture. This perceived discrimination among Muslim communities in diaspora was found to be linked with acculturation strategies [11]. This may be due to the low cultural hybridity and cultural deviance. Cultural hybridity is characterised by a person from a different background who comes to another culture and can become more acceptant of other beliefs, races, languages, and religions [1]. Chiang [13] described the phenomenon very accurately:

"Globalization de-territorializes, the borders of countries and the bounds of cultures become blurred, contested, open-ended, unstable, and frequently modified. On one hand, the mobility and re-placement of our bodies destabilize our traditional sense of identity that was usually deeply rooted in a sense of nation-state. On the other hand, "localism," or "nativism," simultaneously increases as reaction and resistance to the global forces from the locals." (page 29)

Pakistanis in UK seem to have frozen identities. Some studies highlighted the assumption of wives' passivity in arranged migration marriages or in joining husbands overseas $[14,15]$, while others have demonstrated the dearth of studies on experiences of men who migrate to join wives working abroad [1, 10]. According to Sheffer [16] "modern diasporas are actually mirror representations of culture of origin in the host countries because of maintaining strong emotional and material bonding with their homelands'. 
About the forces and frictions of transnational migration, scholars have identified certain push and pull factors. According to these theories, migration occurs because of pressures and counter-pressures from the origin and host countries [2]. Studies on South Asian diaspora demonstrate that the parents who have migrated from South Asia have less happy, poor performing, and less flexible children [17]. A lot of research has been done on postmigration physical and mental health, and social adjustment of immigrants. Lesser empirical evidence is available on premigration struggles, aspirations and attempts of failure. Despite the importance of the topic, no recent study has been published on the migration aspirations, educational capabilities, marriage preferences, and health outcomes in association with anticipated migration status.

\section{Aims and objectives}

The present study is an interdisciplinary research related to the family studies and marriage, sociology of immigration, and social anthropology. It focuses on the desire-based decision making by individuals regarding voluntary migration. Micro-theories of migration that are based on rational choice theory focus on the factors influencing individual decisions to migrate, which means that how potential migrants calculate the various costs and benefits of migration. The immigrants from developing countries face the challenges of dual cultural scripts and contradicting lifestyles with respect to sexual relationships, socioreligious practices, and even daily routines [18]. This study is based on the planned behaviour theory as theoretical framework $[19,20]$. This theory of Ajzen [21] has been used as theoretical framework for researches on fertility and immigration intentions. It is the purpose of this study to analyse the migration aspiration in association with educational capabilities, marriage preferences and health outcomes as the forces and frictions of transnational migration. A secondary objective is to assess the prevalence of migration desires among the skilled youth in Pakistan.

\section{Methods}

\section{Study design}

A sequential mixed-methods study was conducted in the duration of five months from June to October 2019 among students at University of Lahore, Pakistan. Convenience sampling method has been used to identify the respondents for nine case studies (five males and four females). The data was collected in multiple sittings in the counselling room of School of Integrated Social Sciences, University of Lahore. The students were asked about deductive themes: presence of transnational migration aspiration, how the youth seeks opportunities of migration, importance of seeking nationality of wealthier countries, educational attainment and work experience, English language certification, and immigration advisory service utilisation (see questionnaire in Supplementary Appendix). The case studies data was transcribed and translated into English language. Qualitative data was analysed manually using thematic content analysis. 
Following these nine case studies in the initial phase, a quantitative survey has been conducted among 496 students enrolled in undergraduate and graduate programs at University of Lahore. Data was collected using a self-administered questionnaire comprising 21 items, which was developed based on the qualitative data collected in the first phase of the study and deducted themes from migration literature.

\section{Participants and data collection}

The students who were enrolled in various undergraduate programs and wanted to participate in this study were included in this study. Focussing on students, we assume to recruit participants who are either in a pre-actional or actional stage - according to Ajzen [21] - while acquiring capabilities and finding means of a potential migration intention.

The sample size has been calculated using the prevalence formula [22]:

\section{$N=P(100-P) /(S E)^{2}$}

In the absence of previous studies, the prevalence $(P)$ of migration aspirations is expected to be $50 \%$, with an expected degree of precision (margin for random error [MRE]) of $4.5 \%$, meaning that the true prevalence is between 45.5 to $54.5 \%$. We decided on a $95 \%$ confidence interval $(\mathrm{Cl})$, meaning a $\mathrm{p}$-value < 0.05 being significant $(Z=1.96)$ These assumptions allowed to calculate the standard error (SE) using the following formula: $S E=M R E / Z=4.5 / 1.96=2.29$

This led to the following calculation of the sample size:

\section{$\mathrm{N}=\mathrm{P}(100-\mathrm{P}) /(\mathrm{SE})^{2}$}

\section{$\mathrm{N}=50(100-50) /(2.29)^{2}$}

\section{$\mathrm{N}=2500 / 5.24$}

\section{$\mathrm{N}=477$}

We expected a low non-response rate (less than 5\%). For that reason, the aim was to close the recruitment when about 500 students have been reached. We recruited 497 respondents, out of which 479 provided almost completed questionnaires (with only one or two missings) used for the analyses.

The data was collected in classes that were scheduled in the morning (from 8:00 to 12:00 a.m.). Data were collected by the researchers in cooperation with the concerned administration office of various departments of the University of Lahore, including English Language and Literature, School of Integrated Social Sciences, Computer Science and Information Technology, Electrical Engineering, Mass Communication, Film and TV, Business Studies, Health and Medical Sciences, Sciences and Mathematics. The course instructors announced the study in the class and called for participation in this 
research project. Furthermore, they introduced principal investigator to the students in the last few minutes of the class. The interested students remained seated in the class and filled the self-administered questionnaires in the presence of the principal investigator.

\section{Data analysis}

The quantitative data was analysed using SPSS version 22. Descriptive and bivariate analysis (including chi-squared tests) have been conducted. Binary logistic regression analysis was performed to analyse the data. We tested beforehand for multicollinearity and further requirements for a regression model. Migration aspiration was the dependent variable and we tested its association with baseline characteristics (age, gender, and marital status), work capabilities, and marriage preferences in the

multivariate analyses, as these were the themes derived from the case studies. We used the $\mathrm{R}^{2}$ for testing how much of the variance in the dependent variable is predictable from the independent variables included in the model.

\section{Results}

\section{Qualitative case studies}

The thematic content analysis revealed the following categories: development of subjective capabilities, migration marriage, spouse characteristics linked with permanent resident status (such as social status and financial support), domestic chores, family preferences, as well as social exchange and compromise on match and compatibility. Lack of finances needed for realising immigration was demonstrated in all nine cases. Seven cases reported mental and physical health problems that resulted from overthinking and working towards immigration.

In short, migration marriage was found to have been perceived by most of the case studies as an easy method of getting permanent residence of a high-income country. The people are migrating for economic prosperity while few cases reported dissatisfaction with life chances and environmental threats in developing countries. The data demonstrated that the family preference for searching a spouse of their eligible son or daughter, was mainly determined by the spouse characteristics, which might be same religion and superior socio-economic status with permanent national status. The desires of immigration were depicted strongly by all nine cases. There was a statement quoted three times: "Anything for permanent residence status...".

\section{Socio-demographic characteristics}

The students were aged between 17 and 25 years. Most of them studied health and medical sciences (20.5\%) or Computer Science and Information Technology (20.3\%). Slightly more students were male, although $7 \%$ did not provide information about their gender. However, the majority of male as well as female students agreed to have been possessing migration aspirations. Further socio-demographic characteristics are presented in Table 1, along with the proportion having migration aspirations. 
Significant differences in migration aspirations were found for marital status, education, and study discipline. 
Table 1

Socio-demographic characteristics of respondents $(n=479)$

\begin{tabular}{|llll|}
\hline Variable & $n(\%)$ & $\begin{array}{l}\text { Migration aspiration } \\
n(\%)\end{array}$ & p-value \\
\hline Gender & $198(41.3)$ & $169(85.4)$ & 0.783 \\
Female & $247(51.6)$ & $214(86.6)$ & \\
Male & & & 0.020 \\
Age & $288(60.1)$ & $240(83.3)$ & \\
$\leq 20$ & $188(39.2)$ & $171(91.0)$ & \\
$\geq 21$ & & & \\
\hline Marital status & $88(18.4)$ & $33(37.5)$ & 0.001 \\
Married & $391(81.3)$ & $381(97.4)$ & \\
Unmarried & & & \\
Education completed (in years) & $452(94.4)$ & $387(85.6)$ & \\
12 & $25(5.2)$ & $25(100.0)$ & \\
14 & $2(0.4)$ & $2(100.0)$ & \\
16 & & &
\end{tabular}

a The class strength and daily attendance of the students varies between the departments.

Furthermore, the number of consenting students from various classes was different. 


\begin{tabular}{|llll|}
\hline Variable & $n(\%)$ & Migration aspiration & p-value \\
& & $n(\%)$ & \\
\hline Study discipline ${ }^{\text {a }}$ & $82(17.1)$ & $63(76.8)$ & $59(66.3)$ \\
English & $89(18.6)$ & $82(84.5)$ \\
International Relations & $97(20.3)$ & $22(100.0)$ \\
Computer Science \& IT & $22(4.6)$ & $43(100.0)$ \\
Engineering & $43(9.0)$ & $9(100.0)$ \\
Mass Communication & $9(1.9)$ & $97(99.0)$ \\
Film and TV & $98(20.5)$ & $7(100.0)$ \\
Health \& Medical Sciences & $7(1.5)$ & $13(100.0)$ \\
Mathematics \& Statistics & $13(2.7)$ & $6(100.0)$ \\
Business Studies & $6(1.3)$ & $9(100.0)$ \\
Aviation Management & $9(1.9)$ & \\
Others & & \\
\hline a The class strength and daily attendance of the students varies between the departments. \\
Furthermore, the number of consenting students from various classes was different.
\end{tabular}

\section{Migration aspirations}

The prevalence of migration aspirations among the 479 respondents was very high (86.4\%). However, the majority did not apply for immigration till the time of interview. About three quarter of the respondents think that migration to wealthier countries is a desirable goal in life. $61.2 \%$ of the youth wanted immigration for issues related to work and business. Results indicate that $33.6 \%$ were unsure whereas more than half were hopeful to realise their migration aspirations (Table 2). 
Table 2

Migration aspirations $(n=479)$

\begin{tabular}{|ll|}
\hline Variables & $\boldsymbol{n}(\%)$ \\
\hline Aspiration to migrate to a wealthier country & $414(86.4)$ \\
\hline Applied for immigration to a wealthier country & $125(26.1)$ \\
\hline Migration as a desirable goal in life & $350(73.1)$ \\
\hline Main reason for migration & $293(61.2)$ \\
Work and business opportunities & $78(16.3)$ \\
Nationality status / Stay with foreign national spouse & $82(17.1)$ \\
Family reconciliation & $23(4.8)$ \\
Temporary status (visit only for education / recreational tour) & \\
\hline Confidence about migration & $30(6.3)$ \\
Definitely, I will not get immigration & $25(5.2)$ \\
Most probably, I will not get immigration & $7(1.5)$ \\
Somewhat, I will not get immigration & $161(33.6)$ \\
Can't say & $48(10.0)$ \\
Somewhat, I will get immigration & $122(25.5)$ \\
Most probably, I will get immigration & $81(16.8)$ \\
Definitely, I will get immigration & \\
\hline
\end{tabular}

About the education and work capabilities, $82.3 \%$ reported to have been acquiring degree and language expertise for immigration. Around $65 \%$ believed that the study program that they have chosen is in demand in host country. The marriage preference indicators were also associated with migration aspirations. The majority of the respondents thought that marrying a foreign nationality holder is an easy method of attaining permanent residence status (68.3\%). Parents mostly emphasise the importance of migration $(68.1 \%)$, and a large proportion even emphasises to marry a foreign nationality holder (24.8\%). Interestingly, $30.7 \%$ of respondents confirmed that their family prefers finding a spouse who should be Pakistani by origin and has a similar social background but settled abroad. The respondents were ready to compromise on social status, attractiveness, love, and trustworthiness to marry a person who can serve as means of migration (Table 3 ). 
Table 3

Educational and professional capabilities and marriage preference $(n=479)$

Variable

$n(\%)$

Currently acquiring education and work experience that would helpful for migration

394

(82.3)

Chose study program that is in demand at host country

Marrying a foreign national is an easy way to migrate

Finding a spouse with a foreign nationality with whom one can migrate

Difficult to migrate without marriage

Parents emphasise the importance of migration

Parents emphasise marrying a foreign national holder

Family preferences to find a spouse who is Pakistani and settled abroad

Convinced to compromise on age gap, education and profession in marrying a

Which quality can be compromised in marrying a foreign national spouse?

Social status

Attractiveness

Love

Trustworthiness

Most or all of these

The prevalence of mental illness - indicated by visiting a psychiatrist - as a result of overthinking about immigration was $31.3 \%$. About one quarter of study participants were diagnosed with depression, whereas $15.9 \%$ of respondents reported physical health problems (Table 4). 
Table 4

Mental and physical health issues caused by migration aspiration $(n=479)$

\begin{tabular}{|ll|}
\hline Variable & $\boldsymbol{n}(\%)$ \\
\hline Seen a psychiatrist because of overthinking about immigration & $150(31.3)$ \\
\hline Diagnosed with mental illness due to strong migration desires & $116(24.2)$ \\
Depression & $45(9.4)$ \\
Anxiety & $21(4.4)$ \\
Other & $297(62.0)$ \\
None & \\
Migration aspirations affected physical health & $76(15.9)$ \\
Yes & $138(28.8)$ \\
Unsure & $261(54.5)$ \\
No & \\
\hline
\end{tabular}

\section{Binary Logistic Regression}

Table 5 presents the results of the binary logistic regression model. Age and gender were not significantly associated with migration aspirations. Not being married is - despite a very large $\mathrm{Cl}$ - one of the strongest predictors, as unmarried students are more than 30 times (OR $=30.77,95 \% \mathrm{Cl}$ : 8.56-111.09) as likely to have migrations aspirations compared to married students. Neither parental emphasis of the importance of migration nor their emphasis to marry a foreign national holder is significantly associated with migration aspirations. However, family preferences to find a spouse who is Pakistani and settled abroad are strongly significantly associated with migration aspirations $(\mathrm{OR}=28.27,95 \% \mathrm{Cl}$ : 2.49-320.86, $p=0.007$ ). 
Table 5

Association of migration aspirations with baseline characteristics, education and work capabilities, and marriage preferences $(n=479)$

\begin{tabular}{|c|c|c|}
\hline Variables & OR $(95 \% C I)^{a}$ & $\begin{array}{l}p- \\
\text { value }\end{array}$ \\
\hline Gender & $0.91(0.26-3.16)$ & 0.884 \\
\hline Female & 1 & \\
\hline \multicolumn{3}{|l|}{ Male } \\
\hline Age & $1.80(0.50-6.54)$ & 0.370 \\
\hline$\leq 20$ & 1 & \\
\hline \multicolumn{3}{|l|}{$\geq 21$} \\
\hline Marital status & $\begin{array}{l}30.77(8.56- \\
111.09)\end{array}$ & $<.001$ \\
\hline Unmarried & 1 & \\
\hline Married & & \\
\hline $\begin{array}{l}\text { Currently acquiring education and work experience that would helpful } \\
\text { for migration }\end{array}$ & $\begin{array}{l}6.07(1.49- \\
24.73)\end{array}$ & 0.012 \\
\hline Yes & 1 & \\
\hline \multicolumn{3}{|l|}{ No } \\
\hline Chose study program that is in demand at host country & $\begin{array}{l}4.94(1.33- \\
18.30)\end{array}$ & 0.017 \\
\hline Yes & 1 & \\
\hline No & & \\
\hline Marrying a foreign national is an easy way to migrate & $0.13(0.03-0.55)$ & 0.005 \\
\hline Yes & 1 & \\
\hline \multicolumn{3}{|l|}{ No } \\
\hline Finding a spouse with a foreign nationality with whom one can migrate & $\begin{array}{l}8.35(1.07- \\
65.46)\end{array}$ & 0.043 \\
\hline No & 1 & \\
\hline Parents emphasise the importance of migration & $0.39(0.10-1.55)$ & 0.179 \\
\hline Yes & 1 & \\
\hline No & & \\
\hline
\end{tabular}

a Reference category: No migration aspirations 


\section{Variables}

$\operatorname{OR}(95 \% C I)^{a}$

p-
value

Parents emphasise marrying a foreign national holder

$0.57(0.07-4.52) \quad 0.596$

Yes

1

No

Family preferences to find a spouse who is Pakistani and settled abroad

$28.27(2.49-$

320.86)

0.007

Yes

1

No

${ }^{\text {a }}$ Reference category: No migration aspirations

Students currently acquiring education and work experience that would helpful for migration $(\mathrm{OR}=6.07$, $95 \% \mathrm{Cl}: 1.49-24.73, p=0.012)$ and students who chose a study program that is in demand at host country (OR $=4.94,95 \% \mathrm{Cl}: 1.33-18.30, p=0.017)$ are more likely to have migration aspirations. Judging marriage as an easy way for migration is reversely associated with migration aspirations ( $O R=0.13,95 \%$ Cl: $0.03-0.55, p=0.005)$. The variables included in the model explained a very high proportion of the total variance $(80.2 \%)$, even when excluding marital status $(72.9 \%)$, family preferences on spouses being Pakistani but settled abroad (77.4\%), or both of these variables $(68.6 \%)$ from the model.

\section{Discussion}

The findings of this study demonstrate the association of migration aspirations with educational and professional capabilities, marriage preferences, and health outcomes. Our study population of skilled youth in Pakistan has high aspirations about migrating to a wealthier country, which even drives them to compromise on their ideal spouse characteristics. This is consistent with previous studies indicating that they are likely to marry a person with high age difference as well as with missing emotional and intellectual compatibility [4]. In such cases, the immigrants are unable to contribute into the labour force and, therefore, become an indirect burden for the destination country.

Interventions should target counselling youth living in diaspora in the long run for avoiding social problems. Potential migrants acquire skills and education that might be helpful for migration and integration into the host country. However, one needs to avoid a brain drain, where highly skilled youths migrate to another country. This has already been visible among Pakistanis migrating for example to the United States to study abroad and to stay in that destination country afterwards [23]. The results of or study even show that students aim to acquire a high level of education in Pakistan itself, because it supports their migration plans.

Compromise on spouse characteristics like trustworthiness and social status was linked with assumption of getting help in achieving migration goals. The qualitative data highlights that migration marriages are 
preferred in seven out of nine youth cases. This trend of migration marriage is linked with readiness to compromise on spouse characteristics and exchange youth and beauty for permanent residency status. There are further studies, indicating that contemporary immigration from Pakistan to the United Kingdom, which frequently takes place in form of a marriage migration, reveals a complex of social and economic pressures in the early months and years after migration. In men, this kind of migration may result in contradictory implications for masculinity [24]. Research also indicates that migration marriages may offer socioeconomic benefits in the destination country, if the opportunity of migration attracts a more highly educated spouse. However, the translation of educational capital into socioeconomic benefits is mediated by the labour market position of migrant spouses [25].

The global trends of skilled outward migration demonstrate that the brain drain is a universal phenomenon for developing countries. In times of a demand of high-quality skilled labour workers, industrialized countries accommodate migrants from developing countries compensate for this demand. However, according to the International Labour Organization [26], high-income countries have lowered this intake to protect the economic rights of local citizens. Despite these revisions in migration as well as social policies, there is still a large proportion of Pakistani youths having migration aspirations.

Irrespective of potential inconsistencies in individual migration behaviour [20], which may occur because of missing opportunities or incentives for migration, one needs to consider the large impact on health. This study emphasises that a large proportion of youths with migration aspirations are affected by psychological distress. Therefore, there is a need to solve this area of conflict by implementing local, national, and global initiatives.

\section{Limitations}

This study presents a limited scenario of one private sector university located in Lahore, Pakistan. Moreover, due to shortage of resources and time, the scope of this study was kept limited to undergraduate students. However, mixing of research methods and generation of similar findings from quantitative and qualitative studies allowed careful external validity. The findings of this study are not comparable to any pre-existing literature, because of the absence of any such study among Pakistani skilled youth and their aspirations related to transnational migration.

\section{Conclusion}

This study demonstrates the association of migration aspirations with socio-demographic characteristics, educational capabilities, marriage preferences, and health outcomes. Results clearly show that youths acquire skills and education that would helpful for migration. The opportunity of migration may attract potential spouses (Pakistani raised) with higher levels of education, unequal status of beauty, and with higher age difference. This highlights the reasons behind resistance to acculturation and double standards about host culture. The migration marriages are a depiction of this gross mentality, which requires attention within Pakistani and host countries of migrants. 


\begin{abstract}
Abbreviations
$\mathrm{Cl}$ Confidence interval

P Prevalence

MRE Margin of random error
\end{abstract}

OR Odds ratio

SE Standard error

UK United Kingdom

\title{
DECLARATONS
}

\section{Ethical Approval and Consent to Participate}

The Advanced Studies and Review Board, University of the Punjab Lahore (Pakistan), provided ethical approval for this study. Written informed consent was obtained from respondents before starting the interviews. Respondents were informed about their rights for volunteer participation. Moreover, the researcher also ensured the confidentiality and anonymity of participants, and their responses.

\section{Declarations}

\section{Ethical Approval and Consent to Participate}

The Advanced Studies and Review Board, University of the Punjab Lahore (Pakistan), provided ethical approval for this study. Written informed consent was obtained from respondents before starting the interviews. Respondents were informed about their rights for volunteer participation. Moreover, the researcher also ensured the confidentiality and anonymity of participants, and their responses.

\section{Consent for Publication}

Not applicable.

\section{Availability of Data and Materials}

Data is available from authors upon reasonable request.

\section{Competing Interest}

The authors declare that no competing interest exist. FF serves on the Editorial Board of BMC Public Health as Associate Editor.

\section{Funding}


This research received no supporting funds from any funding agency in the public, commercial, or not-forprofit sector.

\section{Authors Contributions}

The study was conceptualized by AJ. AJ conducted data collection and analysis, FF supervised this process. AJ drafted the manuscript, FF revised it critically for important intellectual content. All authors reviewed and approved the final version of the manuscript.

\section{Acknowledgements}

Not applicable.

\section{References}

1. Balistreri KS, Joyner K, Kao G. Trading youth for citizenship? The spousal age gap in cross-border marriages. Popul Dev Rev. 2017;43(3):443.

2. Virupaksha HG, Kumar A, Nirmala BP. Migration and mental health: An interface. Journal of Natural Science Biology Medicine. 2014;5(2):233.

3. IOM. Global Migration Indicators. UN Migration; Global Migration Data Analysis Center. Brussels: International Organization of Migration; 2018.

4. Charsley K. Risk, trust, gender and transnational cousin marriage among British Pakistanis. Ethnic Racial Studies. 2007;30(6):1117-31.

5. Lu M. Transnational marriage in Asia. Leiden: IIAS; 2007.

6. Meszaros J. Marriage migration as a pathway to citizenship: Filipina brides, economic security, and ideas of global hypergamy. In: Fresnoza-Flot A, Ricordeau G, editors. International Marriages and Marital Citizenship - Southeast Asian Women on the Move. New York: Routledge; 2017. pp. 45-60.

7. Le DB, Truong TD, Khuat TH. Transnational Marriage Migration and the East Asian Family-Based Welfare Model: Social Reproduction in Vietnam, Taiwan, and South Korea. In: Truong R-D, Gasper D, Handmaker J, Bergh SI, editors. Migration, Gender and Social Justice. Berlin/Heidelberg: Springer; 2014. pp. 87-103.

8. Mansoor A. "Marginalization" in third world feminism: Its problematics and theoretical reconfiguration. Palgrave Communications. 2016;2:16026.

9. Eggeb $\varnothing \mathrm{H}$. A real marriage? Applying for marriage migration to Norway. Journal of Ethnic Migration Studies. 2013;39(5):773-89.

10. Charsley K, Shaw A. South Asian transnational marriages in comparative perspective. Glob Netw. 2006;6(4):331-44.

11. Robinson L. Cultural identity and acculturation preferences among South Asian adolescents in Britain: An exploratory study. Children Society. 2009;23(6):442-54. 
12. Werbner P. Theorising complex diasporas: purity and hybridity in the South Asian public sphere in Britain. Journal of Ethnic Migration Studies. 2004;30(5):895-911.

13. Chiang CY. Diasporic theorizing paradigm on cultural identity. Intercultural Communication Studies. 2010;19(1):29-46.

14. King R, Collyer M. Migration and development framework and its links to integration. In: GarcésMascareñas B, Penninx R, editors. Integration Processes and Policies in Europe. Cham: Springer; 2016. pp. 167-88.

15. Shuval JT. Diaspora migration: Definitional ambiguities and a theoretical paradigm. International Migration. 2000;38(5):41-56.

16. Sheffer G. Modern diasporas in international politics. London: Taylor \& Francis; 1986.

17. Jordan LP, Graham E. Resilience and well-being among children of migrant parents in South-East Asia. Child Dev. 2012;83(5):1672-88.

18. Zaidi AU, Couture-Carron A, Maticka-Tyndale E. 'Should I or Should I Not'?: an exploration of South Asian youth's resistance to cultural deviancy. International Journal of Adolescence Youth. 2016;21(2):232-51.

19. Ajzen I, Klobas J. Fertility intentions: An approach based on the theory of planned behavior. Demographic Research. 2013;29:203-32.

20. Lu M. Do people move when they say they will? Inconsistencies in individual migration behavior. Popul Environ. 1999;20(5):467-88.

21. Ajzen I. From intentions to actions: A theory of planned behavior. In: Kuhi J, Beckmann J, editors. Action control: From cognition to behaviour. Heidelberg: Springer; 1985. pp. 11-39.

22. Fox N, Hunn A, Mathers N. Sampling and sample size calculation. In: Research Design Service for the East Midlands/Yorkshire \& the Humber. East Midlands/Yorkshire: The National Institutes for Health Research; 2009.

23. Orton JW. Brain drain of Pakistani professionals in the United States. Pakistan Economic Social Review. 1982;20(1):30-5.

24. Charsley K, Ersanilli E. The „Mangetar Trap'? Work, family and Pakistani migrant husbands. Norma. 2017;14(2):128-45.

25. Ersanilli E, Charsley K. A Good Match? Education, Labour Market Position, and British South Asian Transnational Marriage. Eur Sociol Rev. 2019;35(1):133-46.

26. International Labour Organization. Research Project Making Migration A Development Factor: The Case of North and West Africa - A review of international migration policies. Geneva: Graduate Institute of International and Development Studies; 2010.

\section{Additional files.}

28. Additional. file 1, Supplementary Appendix, Questionnaire.

\section{Supplementary Files}


This is a list of supplementary files associated with this preprint. Click to download.

- SupplementaryAppendixQuestionnaire.docx 